\title{
Effect of Correlations of Component Failures and Cross-Connections of EDGs on Seismically Induced Core Damages of a Multi-Unit Site*
}

\author{
Ken MURAMATSU**, Qiao LIU** and Tomoaki UCHIYAMA*** \\ ${ }^{* *}$ Nuclear Safety Research Center, Japan Atomic Energy Agency \\ 2-4 Shiragata-Shirane, Tokai-Mura, Ibaraki, Japan \\ E-mail:\{muramatsu.ken, liu.qiao\}@jaea.go.jp \\ *** Computer Simulation \& Analysis of Japan Co. Ltd \\ 1-3-9 Shibadaimon, Minato-ku, Tokyo, Japan
}

\begin{abstract}
Aiming at proposing effective applications of seismic probabilistic safety assessment (PSA) for design and risk management of nuclear facilities, we conducted a preliminary seismic PSA study for a multi-unit site to examine core damage frequency (CDF) and core damage sequences with consideration of the effect of correlations of component failures. In addition, we also examined the effectiveness of an accident management measure, namely, cross-connections of emergency diesel generators (EDGs) between adjacent units in this study. Twin BWR-5 units of the same design were hypothesized to be located at the same site in this study and the CDF as well as the accident sequences of this two-unit site were analyzed by using SECOM2, a system reliability analysis code for seismic PSA. The results showed that the calculated CDF was dependent on the assumptions on the correlations of component failures. When the rules for assigning correlation coefficients of component responses defined in the NUREG-1150 program were adopted, the CDF of a single unit, the CDF of this two-unit site (the frequency of core damages of at least one unit at this site) and the frequency of simultaneous core damages of both units increased by factors of about 1.3, 1.2 and 2.3, respectively. In addition, it might be possible that the simultaneous core damages of both units are caused by different accident sequence pairs as well as the same sequence pairs. When cross-connections of EDGs between two units were available, the CDF of a single unit, the CDF of this two-unit site as well as the frequency of simultaneous core damages of both units decreased. In addition, the CDF of this two-unit site was smaller than the CDF of a single unit site. These results show that cross-connections of EDGs might be beneficial for a multi-unit site if the rules for assigning correlation coefficients defined in NUREG-1150 program are reasonable.
\end{abstract}

Key words: Seismic PSA, Correlations of Component Failures, Core Damage Frequency, Core Damage Sequence

\section{Introduction}

Seismic probabilistic safety assessment (PSA) of Nuclear Power Plants (NPPs) has been widely conducted since early 1980 s to evaluate core damage frequency (CDF) due to earthquakes and to identify the vulnerability of $\mathrm{NPPs}^{1-6}$. Since Japan is an earthquake-ridden country, the safety concern of NPPs against earthquake is high. To 
investigate the possibility of the CD of a NPP due to earthquakes, Japan Atomic Energy Agency (JAEA, formerly Japan Atomic Energy Research Institute (JAERI)) has been conducting methodology development of seismic PSA since 1986. The SHEAT (Seismic Hazard Evaluation for Assessing the Threat to a Facility Site) code was developed to perform seismic hazard analysis ${ }^{7}$. In addition, the SECOM2 (Seismic Core Melt Frequency Evaluation Code, version 2) code was developed to perform system reliability analysis ${ }^{8-9}$. This seismic PSA method has been applied to a hypothetical BWR plant and the applicability of this methodology has been confirmed ${ }^{10}$.

Since there are generally more than one NPP units at a site in Japan, it is desirable to perform seismic PSA on multiple units at the same site to understand the effect of earthquake on $\mathrm{CDF}$ and core damage sequences of these multiple units. As for internal event, it is natural to expect that if two units are completely independent from each other, the CDF of this two-unit site (the frequency of core damages of at least one unit at this site) will be 2 times of the CDF of a single unit site. However, in the case of earthquake, the CDF of the two-unit site will be less than 2 times of the CDF of a single unit site because earthquake is a common cause event that might cause simultaneous core damages of both units. In addition, correlations of component failures have an important effect on CDF in seismic PSA. In an earlier study it was pointed out that the difference between assuming complete correlations and complete independence could lead to an order of magnitude difference in $\mathrm{CDF}^{11}$. Though the effect of correlations of components on CDF may not be that significant ${ }^{12-14}$, the effect of correlations of components on the CDF of a multi-unit site needs to be investigated.

Further, cross-connections of emergency diesel generators (EDGs) between adjacent units have been shown to be an effective accident management (AM) measure by PSAs for internal events. However, the effectiveness of this AM measure in case of earthquake needs to be examined.

In this study, twin hypothetical units located at the same site are taken as an example and the effect of correlations of component failures and cross-connections of EDGs on CDF and core damage sequences of this site are analyzed by using SECOM2. In Section 2, the seismic PSA procedures of JAEA are briefly introduced. Then the information of the models of the twin units as well as the cases to be analyzed is described in Section 3. The effect of correlations of component failures as well as cross-connections of EDGs on CDF and core damage sequences is discussed in Section 4. Finally, conclusions are given in Section 5.

\section{Seismic PSA Methodology of JAEA}

As shown in Fig.1, the seismic PSA procedures developed in JAEA includes the following five steps ${ }^{15-16}$ :

(1) Evaluation of seismic hazard. The seismic hazard of a given site is defined as the frequency plot of earthquake motion exceeding different levels of intensity (expressed by peak acceleration) at bedrock and is evaluated based on historical earthquake data and active fault data.

(2) Evaluation of component responses and capacities. The responses of components are calculated with the use of the response factor method ${ }^{14}$. The capacities of components are determined by detailed analysis, test data and generic fragility data. The responses (as well as capacities) of components can be correlated or be independent.

(3) Evaluation of component failure probabilities. Component failure probabilities are calculated as a function of the peak acceleration at bedrock by comparing the realistic responses with the capacities of components.

(4) Evaluation of conditional probability of core damage. The conditional probability of core damage on every level of earthquake motion is evaluated using a system model such as FT. 
(5) Evaluation of CDF. The CDF is calculated based on the conditional probability of core damage on each level of earthquake motion and the seismic hazard curve.

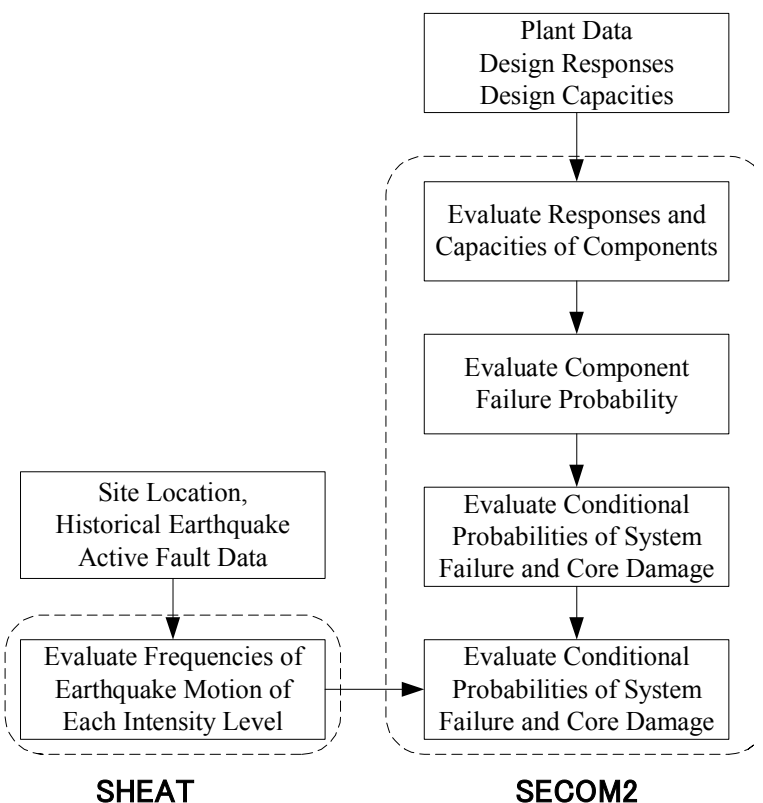

Fig. 1 Seismic PSA procedures developed at JAEA.

In Fig. 1 the SHEAT code is used to evaluate seismic hazard and the SECOM2 code is used to perform system reliability analysis. Details of SECOM2 could be referred to Ref. 8 .

\section{Model Description}

The objective of this study was to examine the effect of correlations of component failures and cross-connections of EDGs on CDF and core damage sequences of a multi-unit site. Two units at the same site were taken as the subject of this study since the results from studying this two-unit site could also be applicable to a multi-unit site.

Twin hypothetical plants, each of which was a 1100Mwe BWR/5 plant with Mark-II type containment, were taken as an example. These twin units were located at an actual site of NPPs on the Pacific coast of the northeastern area of Japan, which was the same as that used for seismic PSA study of the model plant ${ }^{10}$. Therefore, the seismic hazard curve made for the model plant can be used in this study, too.

These two units shared the startup transformer and the EPS (Emergency Power Supply) of each unit was composed of two separate systems, EPS1 and EPS2, each of which had one EDG. When cross-connections of EDGs were taken into consideration, it was supposed that the EPS1 of one unit was connected to the EPS1 of the other unit, and the EPS2 of one unit was connected to the EPS2 of the other unit. In addition, it was supposed that there were not cross-connections of power between HPCS (High Pressure Core Spray) of the two units, which have dedicated EDGs. The system model of these two units (fault trees, event trees) was constructed based on the system model of the model plant ${ }^{10}$. Necessary corrections, such as cross-connections of EPS between two units, had been added to reflect the difference from that of the model plant. In addition, the design responses and capacities of components used in the Model plant were also adopted in this study.

Four initiating events, i.e., small LOCA (Loss of Coolant Accident), medium LOCA, large LOCA, LOSP (Loss of offsite power) were studied. The accident sequences beginning with these initiating events are shown through Fig. 2-5. The explanation of the characters used for these sequences is shown in Table 1. 


\begin{tabular}{c|c|c|c|c|c|c|c}
\hline \multirow{2}{*}{ Init. Event } & \multirow{2}{*}{ EPS } & \multicolumn{2}{|c|}{$\begin{array}{c}\text { Reactor } \\
\text { Shutdown }\end{array}$} & $\begin{array}{c}\text { High Press. } \\
\text { Injection }\end{array}$ & \multicolumn{2}{c|}{$\begin{array}{c}\text { Low Press. } \\
\text { Injection }\end{array}$} & $\begin{array}{c}\text { Decay Heat } \\
\text { Removal }\end{array}$ \\
\cline { 3 - 7 } & & CRD & SLCS & HPCS & LPCS & LPCI & RHR \\
\hline Large LOCA & & \multicolumn{2}{|c|}{$\mathrm{C}$} & $\mathrm{U}_{2}$ & \multicolumn{2}{|c}{ V } & W \\
\hline $\mathrm{A}$ & $\mathrm{B}$ & \multicolumn{4}{c}{}
\end{tabular}

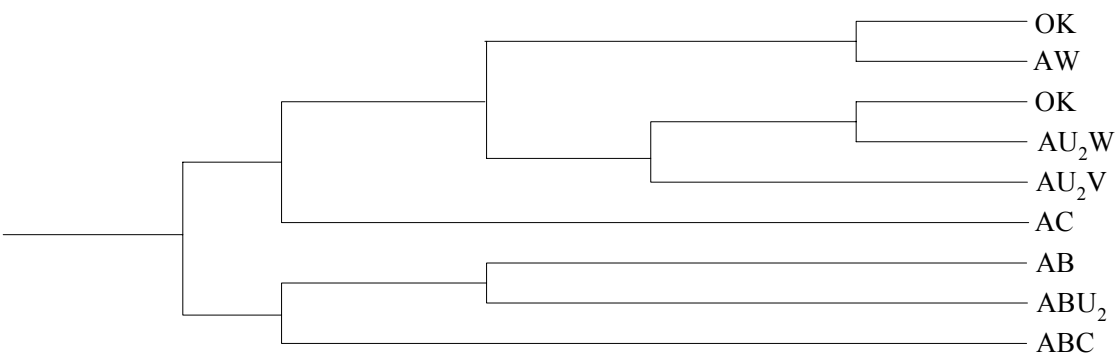

Fig. 2 Event trees initiated by large LOCA.

\begin{tabular}{|c|c|c|c|c|c|c|}
\hline Init. Event & FPS & $\begin{array}{c}\text { Reactor } \\
\text { Shutdown }\end{array}$ & $\begin{array}{c}\text { High Press. } \\
\text { Injection }\end{array}$ & $\begin{array}{l}\text { Reactor } \\
\text { Depress }\end{array}$ & $\begin{array}{l}\text { Low Press. } \\
\text { Injection }\end{array}$ & $\begin{array}{c}\text { Decay Heat } \\
\text { Removal }\end{array}$ \\
\hline $\begin{array}{c}\text { Medium } \\
\text { LOCA }\end{array}$ & & CRD & HPCS & ADS & LPCS LPCI & RHR \\
\hline $\mathrm{S}_{1}$ & $\mathrm{~B}$ & $\mathrm{C}$ & $\mathrm{U}_{2}$ & $\mathrm{X}$ & $\mathrm{V}$ & W \\
\hline
\end{tabular}

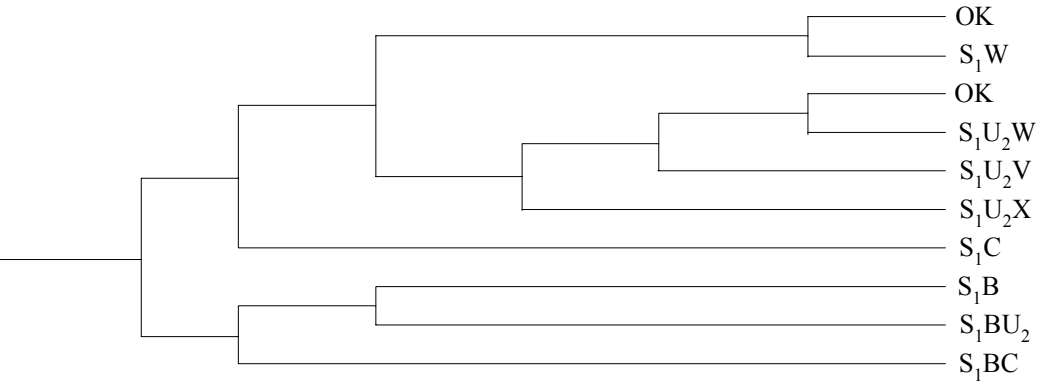

Fig. 3 Event trees initiated by medium LOCA.

\begin{tabular}{c|c|c|c|c|c|c|c|c}
\hline $\begin{array}{c}\text { Init. } \\
\text { Event }\end{array}$ & \multirow{2}{*}{ EPS } & $\begin{array}{c}\text { Reactor } \\
\text { Shutdown }\end{array}$ & \multicolumn{2}{c|}{$\begin{array}{c}\text { High Press. } \\
\text { Injection }\end{array}$} & $\begin{array}{c}\text { Reactor } \\
\text { Depress. }\end{array}$ & $\begin{array}{c}\text { Low Press. } \\
\text { Injection }\end{array}$ & $\begin{array}{c}\text { Decay Heat } \\
\text { Removal }\end{array}$ \\
\cline { 3 - 8 } $\begin{array}{c}\text { Small } \\
\text { LOCA }\end{array}$ & & $\mathrm{CRD}$ & $\mathrm{RCIC}$ & $\mathrm{HPCS}$ & $\mathrm{ADS}$ & LPCS & LPCI & RHR \\
\hline $\mathrm{S}_{2}$ & $\mathrm{~B}$ & $\mathrm{C}$ & $\mathrm{U}_{1}$ & $\mathrm{U}_{2}$ & $\mathrm{X}$ & $\mathrm{V}$ & $\mathrm{W}$ \\
\hline
\end{tabular}

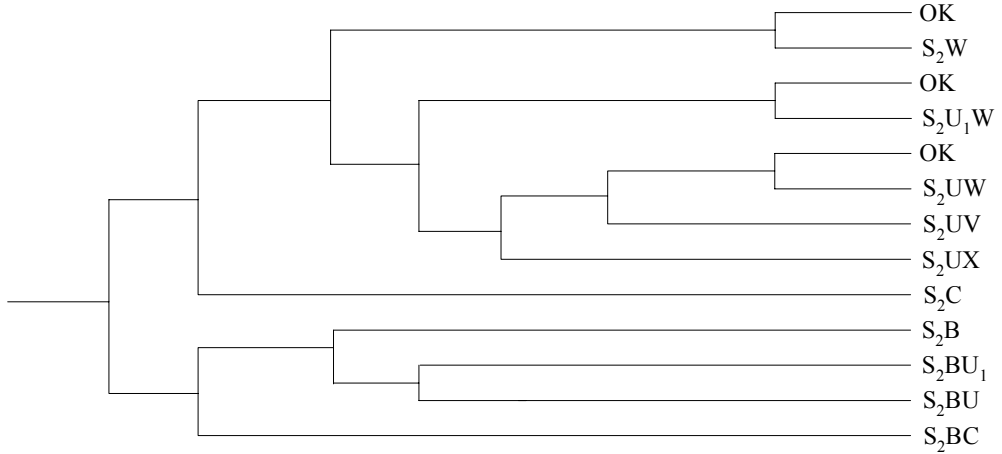

Fig. 4 Event trees initiated by small LOCA. 


\begin{tabular}{|c|c|c|c|c|c|c|c|c|}
\hline $\begin{array}{l}\text { Init. } \\
\text { Event }\end{array}$ & EPS & $\begin{array}{c}\text { Reactor } \\
\text { Shutdown }\end{array}$ & & & & & $\begin{array}{l}\text { Low Press. } \\
\text { Injection }\end{array}$ & \\
\hline LOSP & & \begin{tabular}{l|l} 
CRD & SLCS \\
\end{tabular} & & RCIC & HPCS & DEP & \begin{tabular}{|l|l|} 
LPCS & LPCI \\
\end{tabular} & RHR \\
\hline$T$ & B & $\mathrm{C}$ & & $\mathrm{U}_{1}$ & $\mathrm{U}_{2}$ & $\mathrm{x}$ & & $\mathrm{W}$ \\
\hline
\end{tabular}

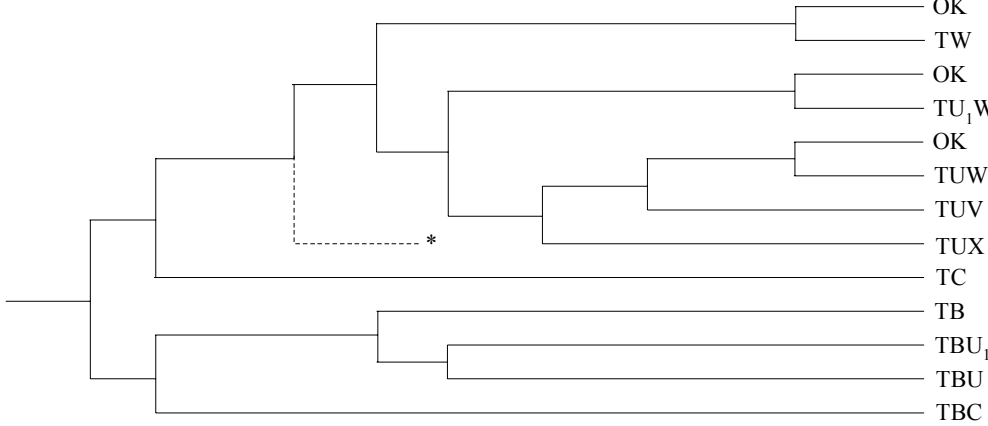

* It is assumed that reactor pressure control always succeeds.

Fig. 5 Event trees initiated by LOSP.

Table 1 Meanings of the characters used in Fig.2 - Fig.5.

\begin{tabular}{|lll|}
\hline Characters & Abbrev. & \multicolumn{1}{c|}{ Full Name } \\
\hline A & L-LOCA & Large Loss of Coolant Accident \\
\hline B & EPS & Emergency Power Supply \\
\hline C & CRD & Control Rod Drive System \\
\cline { 2 - 3 } & SLCS & Standby Liquid Control System \\
\hline S1 & M-LOCA & Medium Loss of Coolant Accident \\
\hline S2 & S-LOCA & Small Loss of Coolant Accident \\
\hline T & LOSP & Loss of Offsite Power \\
\hline U1 & RCIC & Reactor Core Isolation Cooling System \\
\hline U2 & HPCS & High Pressure Core Spray \\
\hline V & LPCI & Low Pressure Coolant Injection \\
\cline { 2 - 3 } & LPCS & Low Pressure Core Spray System \\
\hline W & RHR & Residual Heal Removal System \\
\hline X & DEP & Manual Depressurization \\
\cline { 2 - 3 } & ADS & Automatic Depressurization System \\
\hline
\end{tabular}

In seismic PSA, one important issue that can not be ignored is the effect of the correlations of component failure, which includes correlations of component responses and the correlations of component capacities. Because of lack of information, correlations of component capacities were assumed to be completely independent. Therefore, only correlations of component responses were considered. The correlation coefficients of component responses were determined based on the rules developed in the seismic risk assessment of the Surry and Peach Bottom NPPs ${ }^{17-19}$, which is a part of the NUREG-1150 
$\operatorname{program}^{20}$. The rules for assigning the correlation coefficients of component responses are as shown in Table 2. One thing that should be noted here is that correlations of component responses in different buildings are assumed to be 0 in the NUREG-1150 rules. However, based on the seismic study of NUPEC (Nuclear Power Engineering Corporation, Japan) ${ }^{21}$, even if the components are located in different buildings, if their natural frequencies were similar, the response correlations of these components will be strong. To be conservative, the correlation coefficients of component responses in the same building were also applied to those components in different buildings in this study.

Table 2 Rules for assigning response correlation coefficients in NUREG-1150 program ${ }^{17-19}$

1. Components on the same floor slab, and sensitive to the same spectral frequency range (i.e., zero period accelaration (ZPA), $5-10 \mathrm{~Hz}$, or 10-15 Hz ) will be assigned response correlation coefficient 1.0

2. Components on the same floor slab, sensitive to different ranges of spectral acceleration will be assigned response correlation coefficient 0.5 .

3. Components on different floor slabs (but in the same building) and sensitive to the same spectral frequency range (ZPA, $5-10 \mathrm{~Hz}$ or $10-15 \mathrm{~Hz}$ ) will be assigned response correlation coefficient 0.75 .

4. Components on the ground surface (outside tanks, etc) shall be treated as if they were on the grade floor of an adjacent building.

5. "Ganged" value configurations (either parallel or series) will have response correlation coefficient 1.0

6. All other configurations will have response correlation equal to zero.

To study the effect of correlations as well as the effect of cross-connections of EDSs on seismically induced CDF and core damage sequences, three cases were designed, as shown in Table 3.

Table 3 Three cases to be analyzed in this study

\begin{tabular}{|c|c|c|c|}
\hline & \multicolumn{2}{|c|}{ Condition of Response Correlation } & \multirow{2}{*}{$\begin{array}{l}\text { Whether } \\
\text { cross- } \\
\text { connections } \\
\text { of EDGs are } \\
\text { available or } \\
\text { not? }\end{array}$} \\
\hline & $\begin{array}{r}\text { For Components } \\
\text { in the Same Building }\end{array}$ & $\begin{array}{l}\text { For Components } \\
\text { in Different } \\
\text { Buildings }\end{array}$ & \\
\hline Case 1a & Independent & Independent & No \\
\hline Case $2 \mathrm{a}$ & $\begin{array}{c}\text { Rules of } \\
\text { NUREG-1150 }\end{array}$ & $\begin{array}{c}\text { Rules of } \\
\text { NUREG-1150 }\end{array}$ & No \\
\hline Case $2 b$ & $\begin{array}{c}\text { Rules of } \\
\text { NUREG-1150 }\end{array}$ & $\begin{array}{c}\text { Rules of } \\
\text { NUREG-1150 }\end{array}$ & Yes \\
\hline
\end{tabular}

\section{Results}

4.1 Effect of Correlations of Component Failures on CDF and Core Damage Sequences The calculated seismically induced CDF is shown in Table 4. When correlations of 
component responses was not considered, the CDF of a single unit was $2.29 \times 10^{-5} /$ (Reactor - Year). The CDF of this two-unit site was $4.07 \times 10^{-5} /$ (Reactor - Year) and the frequency of simultaneous core damages of both units was $5.51 \times 10^{-6} /$ (Reactor $\cdot$ Year), respectively. The CDF of this two-unit site was about 1.77 times higher than that of a single unit instead of 2 times because earthquake was a common cause event that it caused simultaneous core damages of both units.

When correlations of component responses were considered, the CDF of a single unit increased to $2.99 \times 10^{-5}$ /(Reactor Year). The CDF of this two-unit site and the frequency of simultaneous core damages of both units increased to $4.76 \times 10^{-5} /$ (Reactor * Year) and 1.27 $\times 10^{-5} /$ (Reactor $\cdot$ Year), respectively.

It is shown that when correlations of component responses were considered, there was a significant increase of the frequency of simultaneous core damages of both units, which was about 2.3 times higher than that with correlations of component responses not considered.

Table 4 Frequency of core damage

\begin{tabular}{|l|c|c|c|}
\hline & $\begin{array}{c}\text { CDF of a } \\
\text { Single Unit } \\
\text { (/Reactor } ~ \\
\text { Year) }\end{array}$ & $\begin{array}{c}\text { CDF of This } \\
\text { Two-Unit } \\
\text { Site* } \\
\text { (/Reactor } \\
\text { Year })\end{array}$ & $\begin{array}{c}\text { Frequency of } \\
\text { Simultaneous Core } \\
\text { Damages of Both } \\
\text { Units } \\
\text { (/Reactor } \cdot \text { Year })\end{array}$ \\
\hline Case 1a & $2.29 \times 10^{-5}$ & $4.07 \times 10^{-5}$ & $5.51 \times 10^{-6}$ \\
\hline Case 2a & $2.99 \times 10^{-5}$ & $4.76 \times 10^{-5}$ & $1.27 \times 10^{-5}$ \\
\hline
\end{tabular}

* Frequency of core damages of at least one unit at the same site.

Table 5 and Table 6 show the top 20 sequences that caused the core damage at this two-unit site in the cases of correlations of component responses being considered or not considered, respectively. The blank items in these tables mean that no core damage happened. It could be observed that when correlations of component responses were considered, the number of the sequence pairs that caused the simultaneous core damages of both units increased. Among the top 20 sequences that caused the core damages at this two-unit site, there were four sequence pairs contributing to the simultaneous core damages in Case 2a. On the contrary, there were no sequence pairs contributing to the simultaneous core damages among the top 20 sequences in Case $1 \mathrm{a}$.

In addition, no matter correlations of component responses were considered or not, there were different sequence pairs contributing to the simultaneous core damages of both units. It seemed that even though the two units had the same design and were located at the same site, the seismically induced simultaneous core damages of both units might be caused by different sequence pairs as well as the same sequence pairs.

Further, it is known from Table 5 that in the sequences such as TB, TBU $1, T B U, S_{2} B$, $\mathrm{S}_{2} \mathrm{BU}$ that caused the core damage of only one unit, if emergency power of the damaged unit could be supplied from the intact one, these sequences would not occur. Therefore, it is suggested to examine the effectiveness of cross-connections of EDGs between these two units in seismic conditions. 
Table 5 Top 20 accident sequences (Case 1a)

\begin{tabular}{|c|c|c|c|c|}
\hline & UnitA & UnitB & Freq. & Ratio \\
\hline 1 & TB & & $4.5 \mathrm{E}-06$ & $11.00 \%$ \\
\hline 2 & & TB & 4.4E-06 & $10.90 \%$ \\
\hline 3 & TW & & $4.4 \mathrm{E}-06$ & $10.70 \%$ \\
\hline 4 & & TW & 4.1E-06 & $10.10 \%$ \\
\hline 5 & TBU1 & & $2.2 \mathrm{E}-06$ & $5.43 \%$ \\
\hline 6 & & $\mathrm{TBU}_{1}$ & $2.2 \mathrm{E}-06$ & $5.39 \%$ \\
\hline 7 & TBU & & $1.1 \mathrm{E}-06$ & $2.68 \%$ \\
\hline 8 & & TBU & $1.1 \mathrm{E}-06$ & $2.66 \%$ \\
\hline 9 & $\mathrm{TU}_{1} \mathrm{~W}$ & & $1.1 \mathrm{E}-06$ & $2.58 \%$ \\
\hline 10 & & $\mathrm{TU}_{1} \mathrm{~W}$ & $1.0 \mathrm{E}-06$ & $2.45 \%$ \\
\hline 11 & $\mathrm{~S}_{2} \mathrm{~B}$ & & $8.0 \mathrm{E}-07$ & $1.97 \%$ \\
\hline 12 & & $\mathrm{~S}_{2} \mathrm{~B}$ & $8.0 \mathrm{E}-07$ & $1.96 \%$ \\
\hline 13 & $\mathrm{~S}_{2} \mathrm{~W}$ & & $5.8 \mathrm{E}-07$ & $1.43 \%$ \\
\hline 14 & & $\mathrm{~S}_{2} \mathrm{~W}$ & $5.7 \mathrm{E}-07$ & $1.40 \%$ \\
\hline 15 & $\mathrm{~S}_{2} \mathrm{BU}_{1}$ & & $3.8 \mathrm{E}-07$ & $0.92 \%$ \\
\hline 16 & & $\mathrm{~S}_{2} \mathrm{BU}_{1}$ & $3.7 \mathrm{E}-07$ & $0.90 \%$ \\
\hline 17 & & $S_{1} B$ & $3.1 \mathrm{E}-07$ & $0.75 \%$ \\
\hline 18 & & $\mathrm{~S}_{2} \mathrm{BU}$ & $3.0 \mathrm{E}-07$ & $0.74 \%$ \\
\hline 19 & $S_{1} B$ & & $3.0 \mathrm{E}-07$ & $0.74 \%$ \\
\hline 20 & & TUX & $3.0 \mathrm{E}-07$ & $0.74 \%$ \\
\hline
\end{tabular}

Table 6 Top 20 accident sequences (Case 2a)

\begin{tabular}{|c|c|c|c|c|}
\hline & UnitA & UnitB & Freq. & Ratio \\
\hline 1 & TB & & $5.1 \mathrm{E}-06$ & $10.80 \%$ \\
\hline 2 & & TB & $5.1 \mathrm{E}-06$ & $10.70 \%$ \\
\hline 3 & TW & & $3.9 \mathrm{E}-06$ & $8.09 \%$ \\
\hline 4 & & TW & $3.8 \mathrm{E}-06$ & $7.88 \%$ \\
\hline 5 & $\mathrm{TBU}_{1}$ & & $2.7 \mathrm{E}-06$ & $5.61 \%$ \\
\hline 6 & & $\mathrm{TBU}_{1}$ & $2.5 \mathrm{E}-06$ & $5.27 \%$ \\
\hline 7 & TB & $\mathrm{TB}$ & $2.1 \mathrm{E}-06$ & $4.49 \%$ \\
\hline 8 & TBU & & $1.1 \mathrm{E}-06$ & $2.31 \%$ \\
\hline 9 & & TBU & $1.1 \mathrm{E}-06$ & $2.29 \%$ \\
\hline 10 & $\mathrm{~S}_{2} \mathrm{~B}$ & & $8.5 \mathrm{E}-07$ & $1.79 \%$ \\
\hline 11 & TBU & TBU & 8.4E-07 & $1.76 \%$ \\
\hline 12 & & $\mathrm{~S}_{2} \mathrm{~B}$ & $8.3 \mathrm{E}-07$ & $1.73 \%$ \\
\hline 13 & $\mathrm{TU}_{1} \mathrm{~W}$ & & 7.9E-07 & $1.67 \%$ \\
\hline 14 & & $\mathrm{TU}_{1} \mathrm{~W}$ & $7.0 \mathrm{E}-07$ & $1.47 \%$ \\
\hline 15 & TB & TBU & $6.0 \mathrm{E}-07$ & $1.27 \%$ \\
\hline 16 & TBU & TB & 5.9E-07 & $1.24 \%$ \\
\hline 17 & $\mathrm{~S}_{2} \mathrm{~W}$ & & $4.1 \mathrm{E}-07$ & $0.87 \%$ \\
\hline 18 & & $\mathrm{~S}_{2} \mathrm{~W}$ & $4.0 \mathrm{E}-07$ & $0.85 \%$ \\
\hline 19 & $\mathrm{~S}_{2} \mathrm{BU}_{1}$ & & 4.0E-07 & $0.83 \%$ \\
\hline 20 & & $\mathrm{~S}_{2} \mathrm{BU}_{1}$ & $3.9 \mathrm{E}-07$ & $0.83 \%$ \\
\hline
\end{tabular}




\subsection{Effect of Cross-Connections of EDGs on CDF and Core Damage Sequences}

When cross-connections of EDGs were considered, the calculated CDF is shown in Table 7 and the top 20 sequences causing the core damages at this site are shown in Table 8.

When cross-connections of EDGs between the two units were available, the CDF of a single unit was $1.97 \times 10^{-5} /$ (Reactor - Year). The CDF of this two-unit site and the frequency of simultaneous core damages of both units were $2.78 \times 10^{-5} /$ (Reactor $\cdot$ Year), and $1.13 \times 10^{-5} /($ Reactor $\cdot$ Year $)$, respectively.

Table 7 Frequency of core damage

\begin{tabular}{|c|c|c|c|}
\hline & $\begin{array}{c}\text { CDF of a } \\
\text { Single Unit } \\
\text { (/Reactor } \\
\text { Year) }\end{array}$ & $\begin{array}{c}\text { CDF of This } \\
\text { Two-Unit Site } \\
\text { (/Reactor } ~ \\
\text { Year) }\end{array}$ & $\begin{array}{c}\text { Frequency of } \\
\text { Simultaneous } \\
\text { Core Damages } \\
\text { of Both Units } \\
\text { (/Reactor } \\
\text { Year) }\end{array}$ \\
\hline Case 2a & $2.99 \times 10^{-5}$ & $4.76 \times 10^{-5}$ & $1.27 \times 10^{-5}$ \\
\hline Case 2b & $1.97 \times 10^{-5}$ & $2.78 \times 10^{-5}$ & $1.13 \times 10^{-5}$ \\
\hline
\end{tabular}

Table 8 Top 20 accident sequences (Case 2b)

\begin{tabular}{|c|c|c|c|c|}
\hline & UnitA & UnitB & Freq. & Ratio \\
\hline 1 & TW & & $4.52 \mathrm{E}-06$ & $16.30 \%$ \\
\hline 2 & & TW & $4.45 \mathrm{E}-06$ & $16.00 \%$ \\
\hline 3 & TB & TB & $2.39 \mathrm{E}-06$ & $8.62 \%$ \\
\hline 4 & TBU & TBU & $8.05 \mathrm{E}-07$ & $2.90 \%$ \\
\hline 5 & $\mathrm{TU}_{1} \mathrm{~W}$ & & $7.39 \mathrm{E}-07$ & $2.66 \%$ \\
\hline 6 & $\mathrm{~S}_{2} \mathrm{~W}$ & & $6.32 \mathrm{E}-07$ & $2.28 \%$ \\
\hline 7 & & $\mathrm{TU}_{1} \mathrm{~W}$ & $6.23 \mathrm{E}-07$ & $2.24 \%$ \\
\hline 8 & $\mathrm{TUX}$ & & $5.96 \mathrm{E}-07$ & $2.15 \%$ \\
\hline 9 & $\mathrm{~TB}$ & $\mathrm{TBU}$ & $5.92 \mathrm{E}-07$ & $2.13 \%$ \\
\hline 10 & & $\mathrm{~S}_{2} \mathrm{~W}$ & $5.85 \mathrm{E}-07$ & $2.11 \%$ \\
\hline 11 & $\mathrm{TBU}$ & $\mathrm{TB}$ & $5.56 \mathrm{E}-07$ & $2.00 \%$ \\
\hline 12 & & $\mathrm{TUX}$ & $5.05 \mathrm{E}-07$ & $1.82 \%$ \\
\hline 13 & $\mathrm{TUW}$ & & $4.36 \mathrm{E}-07$ & $1.57 \%$ \\
\hline 14 & & $\mathrm{TUW}$ & $4.21 \mathrm{E}-07$ & $1.52 \%$ \\
\hline 15 & $\mathrm{TW}$ & $\mathrm{TW}$ & $3.64 \mathrm{E}-07$ & $1.31 \%$ \\
\hline 16 & $\mathrm{TBU}$ & $\mathrm{TBU}$ & $2.86 \mathrm{E}-07$ & $1.03 \%$ \\
\hline 17 & $\mathrm{~S}_{2} \mathrm{~B}$ & $\mathrm{~TB}$ & $2.79 \mathrm{E}-07$ & $1.00 \%$ \\
\hline 18 & $\mathrm{~TB}$ & $\mathrm{~S}_{2} \mathrm{~B}$ & $2.73 \mathrm{E}-07$ & $0.98 \%$ \\
\hline 19 & $\mathrm{TBU}$ & $\mathrm{S}_{2} \mathrm{BU}$ & $2.05 \mathrm{E}-07$ & $0.74 \%$ \\
\hline 20 & $\mathrm{~S}_{1} \mathrm{~W}$ & & $1.97 \mathrm{E}-07$ & $0.71 \%$ \\
\hline & & & & \\
\hline
\end{tabular}

By comparing Table 6 and Table 8, it is known that when cross-connections of EDGs were available, because emergency power could be provided from the other unit in case of the EPS failure of one unit, the sequences such as TB, TBU1, TBU and so on that caused 
the core damage of a single unit in the case of cross-connections of EDGs being not available would not occur. That was why the CDF of a single unit and the CDF of this two-unit site decreased greatly when cross-connections of EDGs between these two units were available.

Further, when cross-connections of EDGs were considered, the CDF of this two-unit site was lower than the CDF of a single unit site. It suggested that the cross-connection of EDGs was an effective way to decrease the frequency of core damages of a multi-unit site.

\section{Conclusions}

This study was performed for seismic PSA study of a multi-unit site to examine the CDF, the potential combination of core damage sequences and the effectiveness of an accident management measure, i.e., the cross-connection of EDGs between adjacent units. SECOM2, which was developed in JAEA for carrying out Level 1 seismic PSA, was used for this analysis. Twin hypothetical units (BWR5 with Mark-II Containment) at the same site were taken as the example. The two units shared the startup transformer and the EPS (Emergency Power Supply) of each unit was composed of two separate systems.

The results showed that the calculated CDF was dependent on the assumptions on the correlations of component failures. When the rules for assigning the correlation coefficients of component responses defined in NUREG-1150 program was adopted, the CDF of a single unit, the CDF of this two-unit site (the frequency of core damages of at least one unit at this site) and the frequency of simultaneous core damages of both units increased by factors of about 1.3, 1.2 and 2.3, respectively. In addition, no matter correlations of component failures was considered or not, it might be possible for the two units to have different accident sequence pairs in addition to the same sequence pairs to cause the simultaneous core damages of both units.

When cross-connections of EDGs were available, the CDF of a single unit, the CDF of this two-unit site and the frequency of simultaneous core damages of both units decreased. In addition, the CDF of this two-unit site was smaller than the CDF of a single unit site. It suggests that cross-connections of EDGs will be beneficial and are worthy of detailed examination for a multi-unit site.

The actual implementation of cross-connection of EDGs will need further examinations such as likelihood of success of manual connections with consideration of available time for operators in TB sequence and cost-benefit comparisons with alternative improvements. Improvements for other dominant sequences such as TW also need to be considered. This paper has shown that the sensitivity study by seismic PSA is an effective tool for identification of candidates for such detailed and practical examinations.

\section{References}

(1) Kennedy, R. P., Cammpbell, R. D., Cornell, C. A., Kaplan, S. and Perla, H., "Probabilistic Seismic Safety Study of an Existing Nuclear Power Plant", Nuclear Engineering and Design, Vol. 59(1980), pp.315-338.

(2) Smith, P. D., Dong, R. G., Bernreuter, D. L., Bohn, M. P., Chuang, T. Y., Cummings, G. E., Johnson, J. J., Mensing, R. W. and Wells, J. E., "Seismic Safety Margins Research Program, Phase I Final Report”, NUREG/CR-2015, 1981.

(3) Kennedy, R. P. and Ravindra, M. K., "Seismic Fragilities for Nuclear Power Plant Risk Studies", Nuclear Engineering and Design, Vol. 79(1984), pp.347-368.

(4) Ravindra, M. K., Kennedy, R. P. and Sues, R. H., "Dominant Contributors to Seismic Risk: an Appraisal ", Report EPRI-NP-3652, 1985.

(5) Shieh, L. C., Johnson, J. J., Wells, J. E., Chen, J. C. and Smith, P. D., "Simplified Seismic PRA: Procedures and Limitations", NUREG/CR-4331, 1985. 
(6) Cummings, G. E., "Summary Report on the Seismic Safety Margins Research Program", NUREG/CR-4331, 1986.

(7) Ebisawa, K., Tanaka, T., Takani, M., Kondo, M. and Abe, K., "Sheat: A Computer Code for Probabilistic Seismic Hazard Analysis- User's manual”, JAERI-Data/Code 94-009, JAERI, Japan, 1994.

(8) Oikawa, T., Kondo, M., Mizuno, Y., Watanabe, Y., Fukuoka, H. and Muramatsu, K., "Development of Systems Reliability Analysis Code SECOM-2 for Seismic PSA", Reliability Engineering \& System Safety, Vol.62(1998), pp.251-271.

(9) Uchiyama, T., Oikawa, T., Kondo, M., Watanabe, Y. and Tamura, K., "User's Manual of Secom2: A Computer Code for Seismic System Reliability Analysis", JAERI-Data/Code 2002-011, JAERI, Japan, 2002.

(10) Risk Analysis Laboratory, "Summary Report of Seismic PSA of BWR Model Plant", JAERI-Research 99-035, JAERI, Japan, 1999.

(11) Budnitz, R. J., "Current Status of Methodologies for Seismic Probabilistic Safety Analysis”, Reliability Engineering and System Safety, Vol. 62 (1998), pp.71-88.

(12) Oikawa, T., Kondo, M., Watanabe, Y., Shiraishi, I., Hirose, J. and Muramatsu, K., "Sensitivity Analyses for the Effect of Uncertainty Issues on Risk Contributors in a Seismic PSA of the BWR Model Plant at JAERI", Proceedings of the OECD/NEA Workshop on Seismic Risk, 1999, pp. 223-249.

(13) Watanabe, Y., Oikawa, T. and Muramatsu, K., "Reappraisal of the Effect of Correlation of Component Failures on Core Damage Frequency in Seismic PSA Using DQFM Method", Proceedings of the OECD/NEA Workshop on Seismic Risk, 1999, pp. 269-295.

(14) Watanabe, Y., Oikawa, T. and Muramatsu, K., "Development of the DQFM Method to Consider the Effect of Correlation of Component Failures in Seismic PSA of Nuclear Power Plant”, Reliability Engineering and System Safety, Vol. 79 (2003), pp265-279.

(15) Muramatsu, K., Ebisawa, K., Matsumoto, K., Oikawa, T., Kondo, M. and Fukuoka, H., "Development of Seismic PSA Methodology at JAERI", Proceeding of Third International Conference on Nuclear Engineering (ICONE-3), 1995, pp. 1333-1340.

(16) Sobajima, M., Muramatsu. K. and Ebisawa, K., "Seismic Probabilistic Safety Assessment Methodology Development and Application to a Model Plant", Proceedings of tenth Pacific Basin Nuclear Conference, 1996, pp. 629-636.

(17) Lambright, J.A., Bohn, M. P., Daniel, S. L., Johnson, J. J., Ravindra, M. K., Hashimoto, P. O., Mraz, M. J., Tong, W. H. and Brosseau. D. A., "Analysis of Core Damage Frequency: Peach Bottom Unit 2 external event”, NUREG/CR-4550, 1989.

(18) Bohn, M. P. and Lambright, J. A., Daniel, S. L., Johnson, J. J., Ravindra, M. K., Hashimoto, P. O., Mraz, M. J., Tong, W. H., "Analysis of Core Damage Frequency: Surry Power Station Unit 1 External Events", NUREG/CR-4550, 1989.

(19) Bohn, M. P. and Lambright, J. A., "Procedures for the External Event Core Damage Frequency Analyses for NUREG-1150”, NUREG/CR-4840, 1990.

(20) USNRC, "Severe Accident Risks: An Assessment for Five U.S. Nuclear Power Plants", NUREG-1150, 1990.

(21) NUPEC, "Report on Developing Seismic PSA-Evaluation of Failure Probability of Building, Constructure and Ramp", INS/M02-16, 2003. 